\title{
Biophysical Chemistry
}

National Cancer Institute

\section{Source}

National Cancer Institute. Biophysical Chemistry. NCI Thesaurus. Code C18119.

The science concerned with phenomena that involve biology, physics, and chemistry principles. 